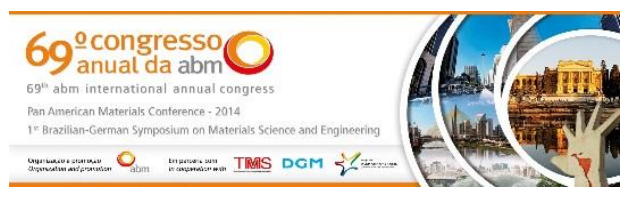

Tema: Materiais cerâmicos, compósitos e poliméricos

\title{
DESENVOLVIMENTO DE MASSAS DE TAMPONAMENTO A BASE DE MATERIAL REFRATÁRIO E ALUMINA PARA VEDAÇÃO DE FUROS DE CORRIDA DE FORNOS DE REDUÇÃO*
}

Robinson Reis Miranda Marcel Mesquita Ferri Júlio Santos Olímpio ${ }^{3}$ Itavahn Alves da Silva ${ }^{4}$

\section{Resumo}

Este trabalho discute o desenvolvimento de massas de tamponamento de furos de corrida de fornos de redução: altos-fornos, fornos de ferros-ligas, cubilôs, entre outros, a partir de resíduos de chamote, materiais refratários, alumina e piche de alcatrão, subproduto da coqueria, utilizado como aglomerante. Foram investigadas as condições de plasticidade, resistência, usinabilidade, moldabilidade e poder de adesão. Os resultados obtidos mostram a possibilidade de emprego industrial destas massas de tamponamento.

Palavras-chave: Furo de corrida; Massa tamponamento; Alumina; Aglomerante.

\section{DEVELOPMENT OF MASSES OF PLUGGING THE BASE AND REFRACTORY MATERIAL AND ALUMINA FOR SEALING HOLES REDUCTION FURNACES RACING}

\section{Abstract}

This work discusses the development of masses of plugging tapholes of reduction reactors: blast furnaces, ferroalloys furnaces, cupola, from waste chamotte, alumina, pitch and tar, coke oven by-product, used as a binding agent. The conditions were investigated of plasticity, resistance, machinability, moldability and adhesion. The results obtained show the possibility of industrial employment of these plugging masses

Keywords: Taphole; Mud plugging; Alumina; Binder.

1 Engenheiro Metalúrgico, Engenheiro de processo, Novelis do Brasil, Ouro Preto, MG, Brasil; robinson.miranda@novelis.com.

2 Engenheiro Metalúrgico, Gerente de fabricação de metal, Novelis do Brasil, Ouro Preto, MG, Brasil; marcel.ferri@novelis.com.

3 Técnico de processo, Novelis do Brasil, Ouro Preto, MG, Brasil; julio.santos@novelis.com.

4 Professor Associado III, Departamento de Engenharia Metalúrgica e de Materiais, Escola de Minas, UFOP, Ouro Preto, MG, Brasil; itavahnufop@yahoo.com.

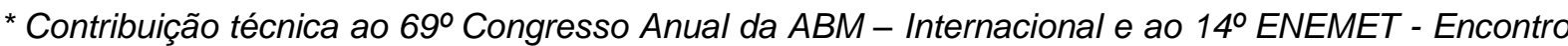
Nacional de Estudantes de Engenharia Metalúrgica, de Materiais e de Minas, 21 a 25 de julho de 2014, São Paulo, SP, Brasil.
} 


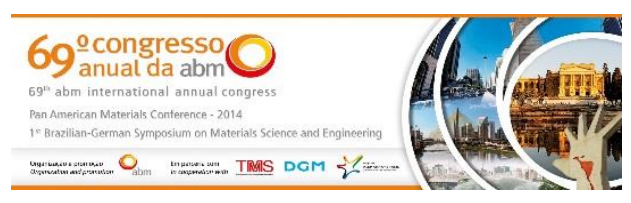

\section{INTRODUÇÃO}

As massas de tamponamento são massas refratárias ordinariamente empregadas no fechamento de furos de corridas de altos-fornos. No caso dos altos-fornos, gusa e escória, acumulados no cadinho, são drenados periodicamente (de duas em duas horas) através de canais de esgotamento, denominados furo de corrida de gusa e/ou de escória. Após a etapa de drenagem do cadinho, é necessário fechar o furo de corrida com massa plástica, injetada por meio de canhão hidráulico ou pneumático. Jamenson et al. [1] apontam que durante o fechamento do furo de corrida do altoforno é necessário uma quantidade extra de massa de tamponamento de recompor a estrutura do cogumelo, o qual prolonga o furo de corrida no interior do cadinho, controla a movimentação do banho e protege a integridade do refratário nas imediações do furo de corrida e do fundo do cadinho, Figura 1.

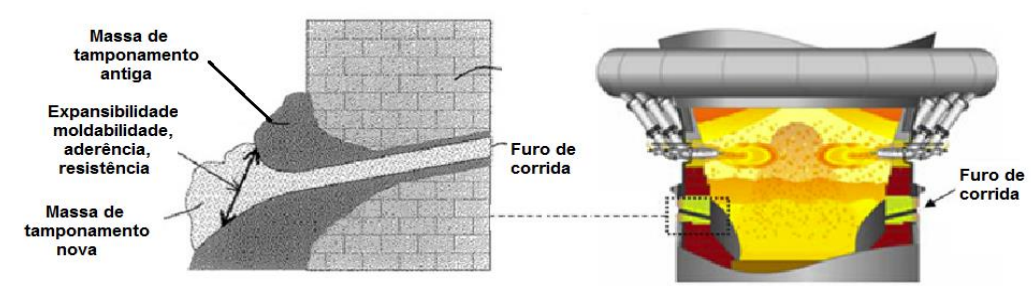

Figura 1: Vista da estrutura da região do furo de corrida de altos-fornos: a) www.neumetallurgy.com; b) MITSUl et al [2].

Wells [2] cita que a estabilidade estrutural do cogumelo e, com isto, o comprimento do furo de corrida, é função da molhabilidade, moldabilidade, densificação, aderência, endurecimento rápido, sinterabilidade e desvolatilização da massa de tamponamento no cadinho. Uma estrutura do cogumelo deficiente volumétrica e estruturalmente comprometem a vida útil do cadinho e, por conseguinte, a campanha do alto-forno. Mitsui et al [2] apontam que a taxa de elevação de temperatura na porção tamponada situada na parede do cadinho é alta, enquanto que na região do cogumelo, devido ao maior volume de massa plástica, é menor de modo que é passível de aparecimento de zona não-seca, a qual é região de fragilização devido à evaporação rápida da umidade e de voláteis da massa de tamponamento, Figura 2.
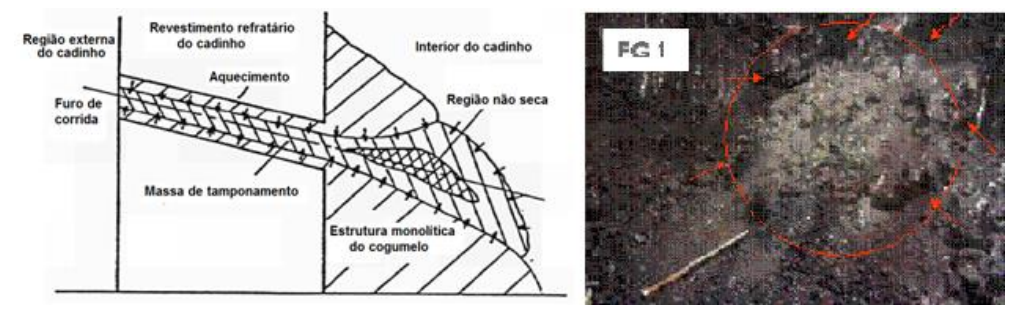

Figura 2: (a) Constituição do cogumelo [2]; b) Cogumelo do furo de corrida 1 do AF \#2 da Arcelor Mittal Tubarão [4].

A massa de tamponamento influi diretamente sobre a produtividade e estabilidade operacional do alto-forno e garante a drenagem regular e estável de gusa e escória. No entanto, a ocorrência dos fenômenos de termoclases térmica, mecânica e química, além da aplicação inadequada da massa de tamponamento, poderá causar o colapso do cogumelo e, com isto, a degradação do revestimento refratário do

\footnotetext{
* Contribuição técnica ao $69^{\circ}$ Congresso Anual da ABM - Internacional e ao 14ํㅡㄹ ENEMET - Encontro Nacional de Estudantes de Engenharia Metalúrgica, de Materiais e de Minas, 21 a 25 de julho de 2014, São Paulo, SP, Brasil.
} 


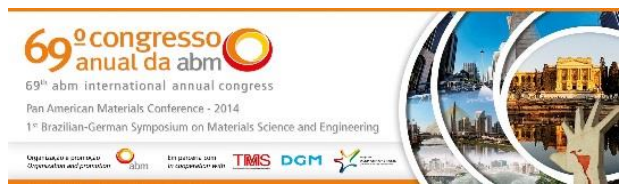

cadinho no entorno do furo de corrida, Figuras 3. Este evento pode ser ainda provocado por vários motivos: perfuração inadequada; existência de trincas e infiltração de líquidos ou em decorrência de tamponamentos sucessivos e deficientes.

No momento de sua aplicação no furo de corrida, o qual se encontra a uma temperatura elevada, o produto é exposto quase que instantaneamente a uma solicitação extremamente severa de calor e da pressão interna do forno. Dessa forma, todo o material que é responsável pela plasticidade da massa (ligante) é eliminado na medida em que o furo é preenchido, ocorrendo à sinterização.

O consumo de massa de tamponamento em altos fornos é função do número, comprimento, diâmetro, ciclo de abertura e perfil de desgaste interno do furo de corrida, além do tamanho e taxa de desgaste do cogumelo.
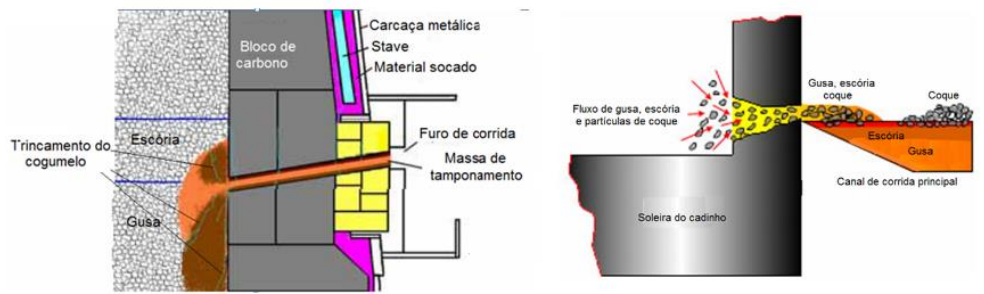

Figura 3. a) Presença de trincas no pedestal do cogumelo acima e abaixo do furo de corrida [5]; b) Colapso do furo de corrida permitindo fuga de partículas de coque junto com o fluxo de gusa e de escória [6].

Para que a massa de tamponamento apresente bom desempenho e garanta estabilidade operacional do AF, ela deve exibir as seguintes características [3,7-10]:

- Ótima plasticidade e fluidez para facilitar o preenchimento do furo de corrida;

- Boa sinterabilidade ou endurecimento rápido, sob as condições térmicas da parede ao longo do furo de corrida;

- Baixa contração volumétrica quando no furo de corrida de modo a assegurar seu selamento;

- Atuar como substrato estável para o novo tamponamento após corridas subsequentes;

- Boa aderência à parede do furo de corrida e no cogumelo no cadinho;

- Boa permeabilidade aos gases gerados pela volatilização do piche e da resina contida;

- Facilidade de perfuração quando da reabertura do furo de corrida para nova operação de drenagem do cadinho;

- Ótima compatibilidade ambiental; facilidade de estocagem sem perda de suas propriedades.

Devido ao fato de que cada furo de corrida do alto-forno fica exposto a vários ciclos de tamponamento, abertura e drenagem de gusa e escória, é imprescindível que a massa de tamponamento empregada apresenta as seguintes propriedades:

- Alta refratariedade e alta estabilidade volumétrica;

- Altas resistências ao choque térmico, à desintegração por monóxido de carbono; à oxidação e ao ataque de álcalis e de zinco;

- Alta resistência à abrasão, erosão e corrosão por ação da escória, gusa e gases durante os períodos de esgotamento do cadinho;

* Contribuição técnica ao 69 Congresso Anual da ABM - Internacional e ao 14 ENEMET - Encontro Nacional de Estudantes de Engenharia Metalúrgica, de Materiais e de Minas, 21 a 25 de julho de 2014, São Paulo, SP, Brasil. 


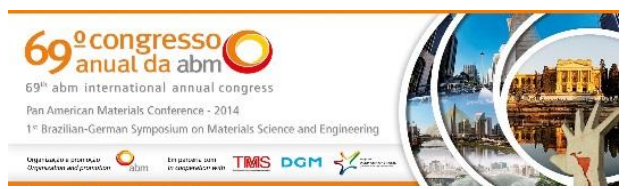

$\mathrm{Na}$ literatura encontram-se estudos complexos de caracterização de cada matériaprima que compõe a massa de tamponamento, mas torna-se importante e primordial no presente trabalho conhecer a atuação e o comportamento de cada material quando estão todos incorporados naquele sistema complexo.

A seleção adequada da mineralogia e distribuição granulométrica do material agregado e dos aditivos da massa de tamponamento são importantes no que tange ao prolongamento da campanha e estabilidade operacional dos altos-fornos. Muroi [7], Wells [2], entre outros, citam que as massas de tamponamento do furo de corrida de altos-fornos são à base de alumina, chamote, pirofilita, cianita e agalmatolito, com a função de conferir refratariedade, resistência à abrasão e erosão, além de garantir estabilidade volumétrica da massa plástica. Enquanto que a incorporação de agentes $\mathrm{FeSi}_{3} \mathrm{~N}_{4}$, FeSi, Al, Si misturas de alumina-sílica, entre outros, visa aumentar a resistência à oxidação, à corrosão e erosão. Já os aditivos, tais como: carbono, piche, resina, argila, têm a função de antiumectantes, lubrificantes, plastificantes.

Embora o uso de resina na massa de tamponamento provoque maior resistência e rápido tempo de endurecimento em comparação com 0 piche, Bassalo \& Bittencourt [9] apontam o emprego de piche como aglomerante permite a restauração do cogumelo, além de evitar o desenvolvimento de trincas. Ademais, aditivos sinterizantes contribuem para o aumento da resistência mecânica. A Figura 4 apresenta as principais matérias-primas e suas funções nas massas de tamponamento.

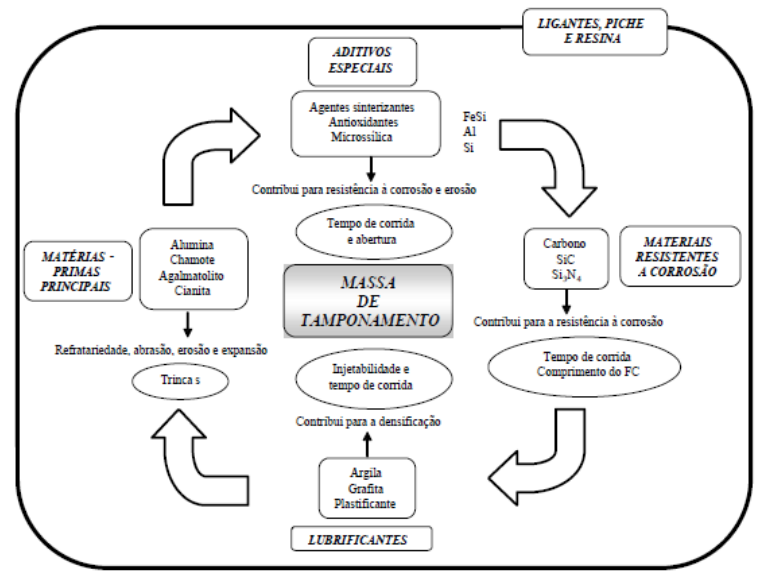

Figura 4. Atribuições de alguns materiais nas massas de tamponamento.

\section{MATERIAL E MÉTODOS}

A escolha da matéria-prima a ser utilizada foi embasada na literatura referente à massa de tamponamento para a indústria siderúrgica (aplicada em Altos-Fornos), e em pesquisas realizadas no decorrer dos testes, referente ao comportamento dos materiais face aos parâmetros físico, químicos e metalúrgicos exigidos. Além disso, procurou-se trabalhar com materiais presentes na própria Fábrica de Pasta.

Para a produção das massas de tamponamento, foram utilizados os seguintes materiais: chamote, alumina, sílica, pós de ferro, grafite, antracito, coque de petróleo, piche, óleo antracênico, todos disponíveis na Novelis do Brasil, Ouro Preto, Minas Gerais. Para a condução dos ensaios, a proporção de aglomerante (piche e óleo antracênico), e a distribuição granulométrica dos materiais agregados, foram

\footnotetext{
* Contribuição técnica ao $69^{\circ}$ Congresso Anual da ABM - Internacional e ao 14ํㅡㄹ ENEMET - Encontro Nacional de Estudantes de Engenharia Metalúrgica, de Materiais e de Minas, 21 a 25 de julho de 2014, São Paulo, SP, Brasil.
} 


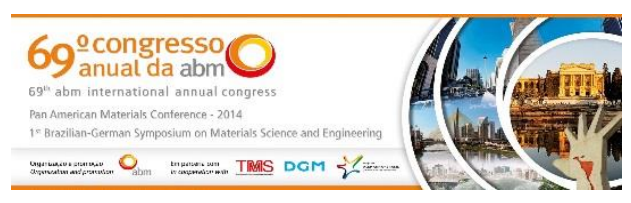

aqueles que propiciassem maior grau de empacotamento, maior compactação, maior moldabilidade, menor consumo de aglomerante e menor tempo de endurecimento do material pós-aplicação.

O processo de desenvolvimento e testes das massas de tamponamento constou das seguintes etapas:

- Escolha da matéria-prima;

- Balanço de massa;

- Elaboração do produto;

- Ensaios em laboratório.

\subsection{Distribuição Granulométrica}

O princípio do empacotamento de partículas consiste basicamente na seleção de tamanhos adequados de partículas, e no proporcionamento entre as quantidades desases tamanhos, visando obter compactos com densidade controlada.

A distribuição granulométrica afeta diretamente o comportamento reológico de suspensões, e quando adequada, permite conciliar alto teor de sólidos com baixa viscosidade.

Um empacotamento denso de partículas consiste em uma estrutura de partículas grandes cujos interstícios são preenchidos por partículas menores, criando novos interstícios que serão preenchidos por partículas ainda menores, e assim sucessivamente. Este empacotamento é diretamente influenciado por alguns fatores, como a correta seleção de tamanhos, o formato e a rugosidade superficial das partículas.

Diversos modelos matemáticos foram propostos, dentre eles, 0 de Andreasen estabelece uma relação de similaridade entre partículas grandes e pequenas.

A equação 1 estabelece a relação de distribuição granulométrica contínua de partículas para o modelo de Andreasen, onde apresenta a relação proporcionalidade de diâmetro médio das partículas.

O princípio do empacotamento de partículas consiste basicamente na seleção de tamanhos adequados de partículas, e no proporcionamento entre as quantidades desases tamanhos, visando obter compactos com densidade controlada.

A distribuição granulométrica afeta diretamente o comportamento reológico de suspensões, e quando adequada, permite conciliar alto teor de sólidos com baixa viscosidade.

Um empacotamento denso de partículas consiste em uma estrutura de partículas grandes cujos interstícios são preenchidos por partículas menores, criando novos interstícios que serão preenchidos por partículas ainda menores, e assim sucessivamente. Este empacotamento é diretamente influenciado por alguns fatores, como a correta seleção de tamanhos, o formato e a rugosidade superficial das partículas.

Diversos modelos matemáticos foram propostos, dentre eles, o de Andreasen estabelece uma relação de similaridade entre partículas grandes e pequenas.

$$
\operatorname{CPFT}(\%)=100\left(\frac{D^{q}-D_{S}^{q}}{D_{L}^{q}-D_{S}^{q}}\right)
$$

\footnotetext{
* Contribuição técnica ao $69^{\circ}$ Congresso Anual da ABM - Internacional e ao 14ํㅡㄹ ENEMET - Encontro Nacional de Estudantes de Engenharia Metalúrgica, de Materiais e de Minas, 21 a 25 de julho de 2014, São Paulo, SP, Brasil.
} 


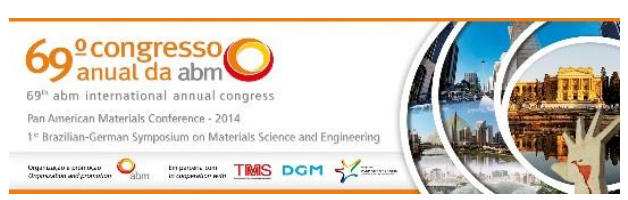

\section{Em que:}

CPFT = é a porcentagem acumulada de partículas menores que Dp;

$\mathrm{Dp}=$ é o diâmetro da partícula;

$\mathrm{DL}=$ é o diâmetro da maior partícula;

$q$ = é o módulo ou coeficiente da distribuição.

\subsection{Aglomerante}

O ligante possui a função de aglomerar as partículas de matérias-primas nas suas mais diferentes granulometrias.

De acordo com a literatura e com os ensaios realizados, quanto menor o uso de materiais finos maior será o consumo de ligante.

O consumo excessivo de ligante implica em menor poder de compactação e maior tempo para endurecimento do material pós-aplicação. Além de alta geração de voláteis, o que pode gerar alteração de propriedades da massa quanto problemas ambientais.

A razão para escolha desse material foi devido à disponibilidade do material e devido não ter havido sucesso na escolha de outros ligantes de menor custo, como o óleo de cozinha e a graxa de uso mecânico.

Ademais, o piche 110 é uma das matérias-primas utilizadas na pasta soderberg e, portanto, um material disponível em grande escala na Fábrica de Pasta.

Os ensaios de viscosidade foram utilizados para estabelecer a melhor proporção entre piche 110 e óleo antracênico. Quanto menor o PA melhor é a plasticidade e melhor a injetabilidade, mais fácil é moldar o material no furo.

O que se espera de um bom material é o comportamento de menor variação possível na viscosidade com o aumento de temperatura, preservando seu poder de aglomeração.

\subsection{Elaboração do Produto}

A mistura de agregado (matéria-prima) e aglomerante foi realizada em um misturado teste, pequeno simulador de produção de no máximo $8 \mathrm{~kg}$ de mistura, Figura 5, localizado na Fábrica de Pasta, a uma temperatura de $90^{\circ} \mathrm{C}$, por um período de 5 a 8 minutos, para que as frações dos agregados e o aglomerante formassem um mistura homogênea.

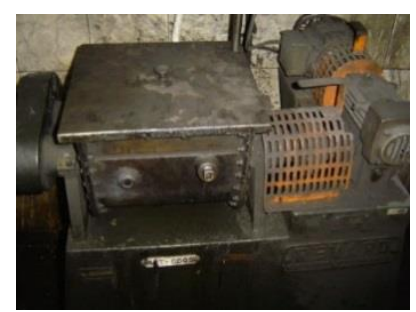

Figura 5. Misturador modelo protótipo.

Depois de pesado às quantidades desejadas de cada componente, cada um deles foi adicionado no misturador. Dando início a etapa de mistura das frações de agregado.

\footnotetext{
* Contribuição técnica ao $69^{\circ}$ Congresso Anual da ABM - Internacional e ao 14ํㅡㄹ ENEMET - Encontro Nacional de Estudantes de Engenharia Metalúrgica, de Materiais e de Minas, 21 a 25 de julho de 2014, São Paulo, SP, Brasil.
} 


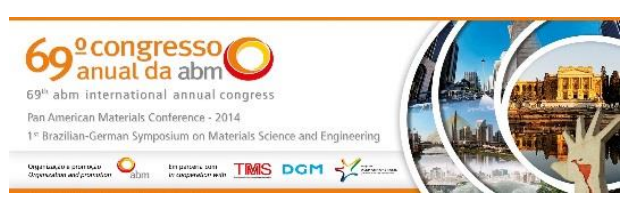

Foi necessário um tempo para que todas as frações de todos os componentes fossem devidamente homogeneizadas.

Depois de pesado às quantidades desejadas de cada componente, cada um deles foi adicionado no misturador. Dando início a etapa de mistura das frações de agregado.

Foi necessário um tempo para que todas as frações de todos os componentes fossem devidamente homogeneizadas.

O tempo de mistura dos agregados de cada teste foi de 3 minutos.

Após a realização da mistura dos agregados, foi adicionado o aglomerante. Novamente foi necessário um tempo de mistura. Nessa etapa, aglomerante e agregado ficaram no misturador por um período de 5 minutos. Resultando em uma mistura de aspecto pastoso, macio e moldável.

\subsection{Calcinação das Amostras}

A calcinação é um dos procedimentos realizados na Fábrica de Pasta com os materiais produzidos, pois pode ser considerada uma boa aproximação do que acontece no ambiente industrial com o produto utilizado.

A partir do material calcinado são realizados vários testes, simulando em laboratório uma resposta às propriedades desejadas no meio industrial.

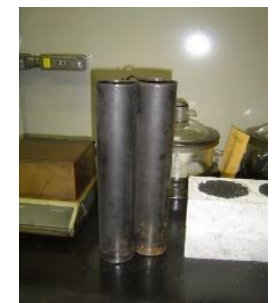

Figura 6. Corpo de prova para calcinação

\subsection{Poder de Pega (aderência) no Refratário}

Entende-se por pega a reação de endurecimento inicial da massa de tamponamento e é caracterizada pela perda da consistência (fluidez) necessária para a aplicação do material.

Este é um teste simples, desenvolvido no laboratório da Fábrica de Pasta. Ele consistiu em moldar em um tijolo refratário um furo cônico e preenche-lo com massa de tamponamento, verde (não calcinada) com o auxílio de um moldador cilíndrico de metal aplicando uma pressão mínima necessária para moldar todo o furo com 0 material.

A Figura 7 apresenta o esboço da massa no tijolo e o teste de densidade.
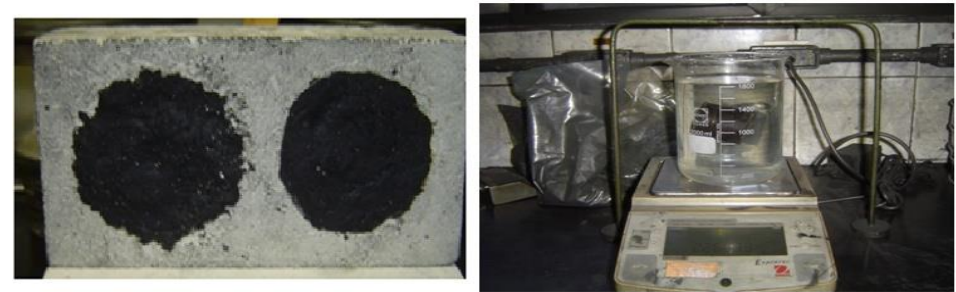

Figura 7. Teste de aderência e densidade.

\footnotetext{
* Contribuição técnica ao 69 Congresso Anual da ABM - Internacional e ao 14ํㅡㄹ ENET - Encontro Nacional de Estudantes de Engenharia Metalúrgica, de Materiais e de Minas, 21 a 25 de julho de 2014, São Paulo, SP, Brasil.
} 


\subsection{Determinação de Plasticidade}

O ensaio de plasticidade mede um dos principais parâmetros das massas de tamponamento. Além de apresentar boa aplicabilidade, ser facilmente moldável, uma excelente condição para a massa de tamponamento é a sua plasticidade.

Este ensaio seguiu o procedimento interno de padrão de testes para materiais de revestimento: PI PO-24-001.O ensaio de plasticidade da massa de tamponamento seguiu o procedimento interno padrão: PI PO-24-001. Neste ensaio utilizaram-se moldes cilíndricos $50 \mathrm{~mm} \times 50 \mathrm{~mm}$, os quais foram mantidos levemente aquecidos e lubrificados com óleo, para facilitar a preparação dos corpos-de-prova. Após moldados, Figura $6 \mathrm{~b}$ os corpos-de-prova foram abrigados em estufa a $300^{\circ} \mathrm{C}$, por um período de 45 minutos. Após este procedimento, foram feitas medidas tridimensionais dos corpos-de-prova. Para a determinação da resistência de compressão do material calcinado, segundo a norma ASTM C 695-1991, utilizou-se presença hidráulica, Figura 6a, e corpo de prova de $6 \mathrm{~cm}$ de diâmetro e $10 \mathrm{~cm}$ de comprimento.

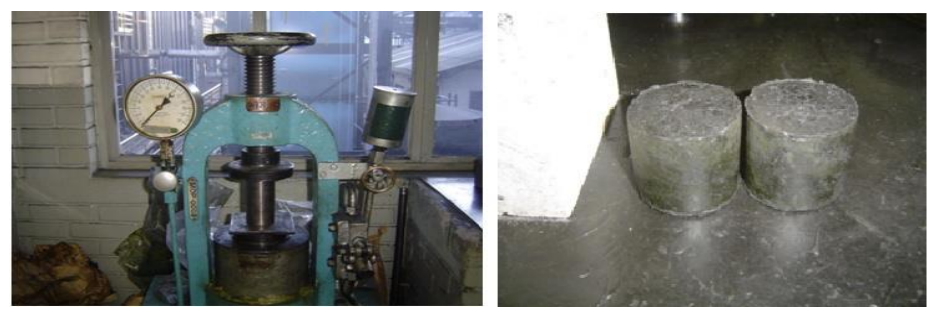

Figura 8. Equipamento para ensaio de resistência à compressão; b) Amostra dos corpos-de-prova.

\section{RESULTADOS}

\subsection{Aglomerante}

O ligante possui a função de aglomerar as partículas de matérias-primas nas suas mais diferentes granulometrias. De acordo com a literatura e com os ensaios realizados, quanto menor o uso de materiais finos maior será o consumo de ligante. O consumo excessivo de ligante implica em menor poder de compactação e maior tempo para endurecimento do material pós-aplicação. Além de alta geração de voláteis, o que pode gerar alteração de propriedades da massa quanto problemas ambientais.

O tipo de ligante utilizado na elaboração da série de massas de tamponamento foi o piche de alcatrão de ponto de amolecimento (PA) 110.

A razão para escolha desse material foi devido à disponibilidade do material e devido não ter havido sucesso na escolha de outros ligantes de menor custo, como o óleo de cozinha e a graxa de uso mecânico.

Ademais, o piche 110 é uma das matérias-primas utilizadas na pasta soderberg e portanto, um material disponível em grande escala na Fábrica de Pasta.

Os ensaios de viscosidade foram utilizados para estabelecer a melhor proporção entre piche 110 e óleo antracênico. Quanto menor o PA melhor é a plasticidade e melhor a injetabilidade, mais fácil é moldar o material no furo.

Os resultados em várias temperaturas estão apresentados na Tabela 1.

\footnotetext{
* Contribuição técnica ao 69 Congresso Anual da ABM - Internacional e ao 14ํㅡㄹ ENET - Encontro Nacional de Estudantes de Engenharia Metalúrgica, de Materiais e de Minas, 21 a 25 de julho de 2014, São Paulo, SP, Brasil.
} 


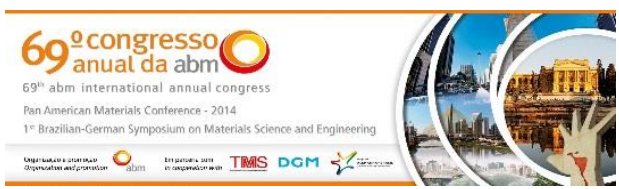

O que se espera de um bom material é o comportamento de menor variação possível na viscosidade com o aumento de temperatura, preservando seu poder de aglomeração.

A relação ideal que se busca para a mistura piche e óleo antracênico é um dos grandes desafios do projeto.

De acordo com os resultados dos testes realizados, foi observada a dificuldade em conseguir aglomerantes que satisfação às condições desejadas.

Até mesmo o baquelite que é considerado um material nobre no ramo dos refratários não atendeu as condições iniciais de fluído Newtoniano.

O que será adotado no trabalho será uma proporção entre piche e óleo que satisfaça as condições de plasticidade e aglomeração e que tenha uma curva de viscosidade mais suave.

Tabela 1: Viscosidade para diferente composições de óleo antracênico e piche de alcatrão.

\begin{tabular}{|l|l|l|l|l|}
\hline T/Visc. & $\begin{array}{l}\text { Óleo/Piche } \\
36 / 65\end{array}$ & $\begin{array}{l}\text { Óleo/Piche } \\
33 / 70\end{array}$ & $\begin{array}{l}\text { Óleo/Piche } \\
26 / 74\end{array}$ & $\begin{array}{l}\text { Óleo/Piche } \\
20 / 80\end{array}$ \\
\hline $\begin{array}{l}\text { Temperatura } \\
{ }^{0} \mathrm{c}\end{array}$ & $\begin{array}{l}\text { Viscosidade } \\
\text { cPoise }\end{array}$ & $\begin{array}{l}\text { Viscosidade } \\
\text { cPoise }\end{array}$ & $\begin{array}{l}\text { Viscosidade } \\
\text { cPoise }\end{array}$ & $\begin{array}{l}\text { Viscosidade } \\
\text { cPoise }\end{array}$ \\
\hline 25 & 8400 & 56000 & 156000 & \\
\hline 30 & 5600 & 21200 & 83000 & 900000 \\
\hline 35 & 3360 & 9100 & 31000 & 232000 \\
\hline 40 & 1900 & 4600 & 15000 & 94000 \\
\hline 45 & 1200 & 2500 & 8000 & 44500 \\
\hline 50 & 750 & 1625 & 4750 & 21800 \\
\hline 55 & 424 & 1300 & 2800 & 12000 \\
\hline 60 & 292 & 940 & 1650 & 7500 \\
\hline
\end{tabular}

De posse dos valores obtidos para viscosidade de várias composições diferentes para o piche 110 e o óleo antracênico construiu-se o gráfico Viscosidade versus temperatura, representado na Figura 12.

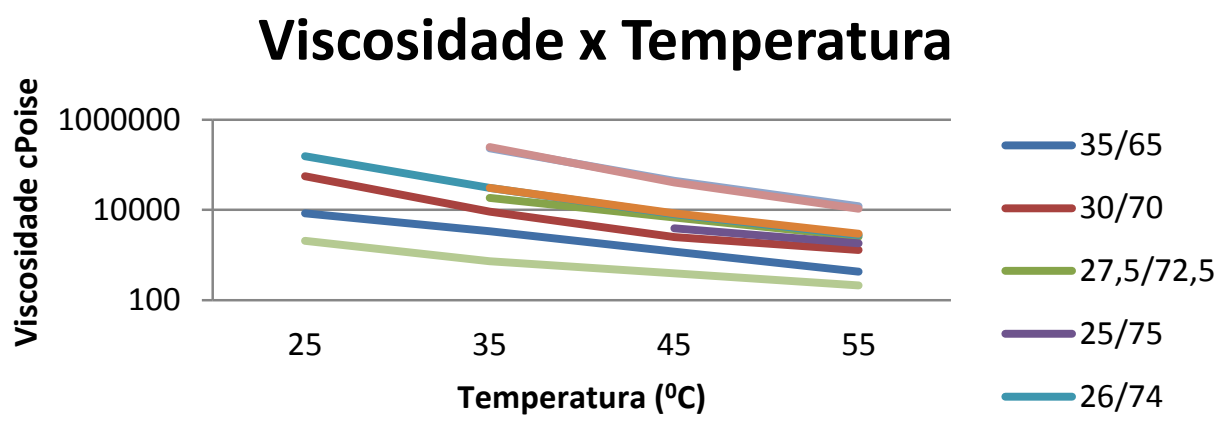

Figura 9. Curva granulométrica da série de massas de tamponamento desenvolvidas.

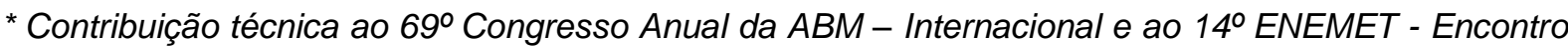
Nacional de Estudantes de Engenharia Metalúrgica, de Materiais e de Minas, 21 a 25 de julho de 2014, São Paulo, SP, Brasil.
} 


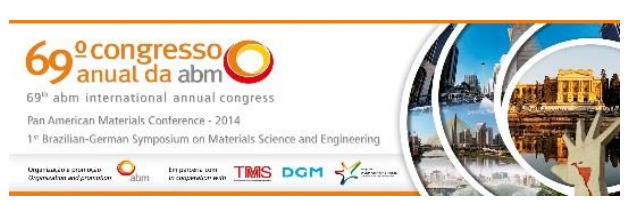

Ponto de amolecimento Piche (85 e 110) x Óleo Antracênico

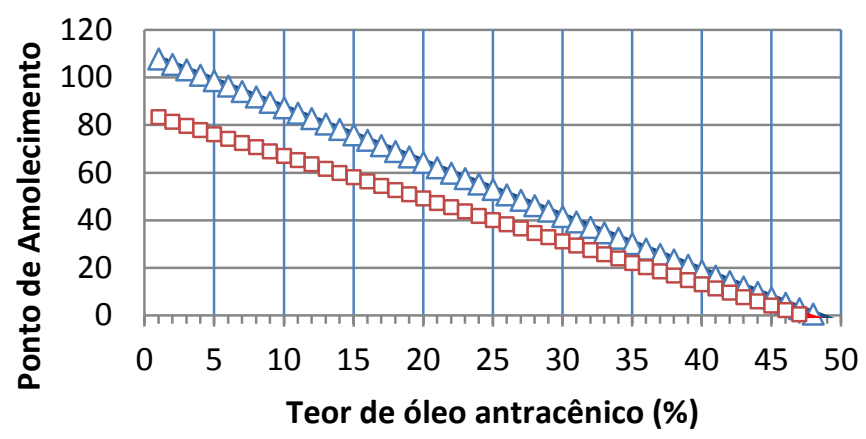

Piche 110:

$Y=-2,28 X$

$+110$

$\triangle$ PA Piche 110

$\square-\mathrm{PA}$ Piche 85

Figura 10: Relação de piche 85 e 110 com Ponto de Amolecimento para composições variadas de aglomerante.

Uma característica fundamental da série de massas de tamponamento desenvolvidas é a possibilidade de utilização de diferentes tipos de matérias-primas, incluindo o fato de se trabalhar com reciclagem. Diante isso, um resultado interessante foi obtido para um produto encontrado na Fábrica de Pasta, o piche 85 que se apresenta em grande quantidade e poderia ser uma maneira interessante de consumir esse material. A Figura 10 apresenta um gráfico obtido a partir de composições variadas de aglomerante.

\subsection{Agregado}

Os testes realizados mostraram-se positivos quanto ao comportamento esperado da massa de tamponamento. Todas as composições desenvolvidas, segundo os testes laboratoriais, estão aptas a serem testadas em escala industrial.

A princípio é importante destacar que não há uma massa melhor que as outras e sim que há uma variação na composição e distribuição granulométrica para cada material desenvolvido, podendo ser adaptado ao ambiente em que se deseja aplicála.

Em determinadas condições uma prevalecerá sobre as outras, atendendo os princípios de operação de cada reator em que for aplicado.

A série de massas desenvolvidas pode ser adaptada a outras condições e padrões de aplicação. A ideia é manter o material base: alumina e materiais refratários, e a partir deles desenvolver outras massas de tampomento. Permitindo a série a possibilidade de ampliação de opções de material de tamponamento.

Valores de densidade da pasta verde, plasticidade, resistência à compressão, teor de cinzas e de voláteis e porosidade das massas de tamponamento investigadas estão mostrados na Tabela 2.

\footnotetext{
* Contribuição técnica ao 69 Congresso Anual da ABM - Internacional e ao 14ํㅡㄹ ENEMET - Encontro Nacional de Estudantes de Engenharia Metalúrgica, de Materiais e de Minas, 21 a 25 de julho de 2014, São Paulo, SP, Brasil.
} 


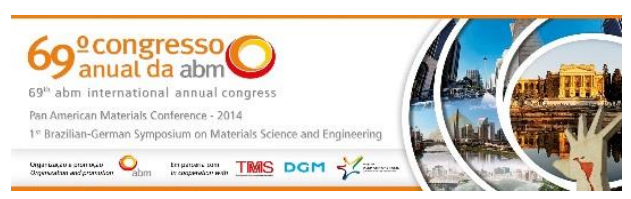

Tabela 2: Quadro de resultados dos ensaios realizados nas massas de tamponamento desenvolvidas.

\begin{tabular}{|c|c|c|c|c|}
\hline Propriedade & MASSA T6 & $\begin{array}{l}\text { MASSA } \\
\text { T14 }\end{array}$ & $\begin{array}{l}\text { MASSA } \\
\text { T16 }\end{array}$ & Referência \\
\hline Densidade Pasta Verde $\left(\mathrm{g} / \mathrm{cm}^{3}\right)$ & 2,22 & 2,29 & 2,3 & ASTM C 559-1990 \\
\hline Plasticidade (\%) & 35,65 & 68,3 & ALTA & PI PO-24-001 \\
\hline $\begin{array}{lll}\begin{array}{l}\text { Resistência } \\
\left(\mathrm{Kg} / \mathrm{cm}^{2}\right)\end{array} & \text { a } & \text { Compressão } \\
\end{array}$ & 61,27 & 238,09 & 174,09 & ASTM C 695-1991 \\
\hline $\begin{array}{ll}\text { Resistividade } & \text { Elétrica } \\
\left(\mathrm{Ohm} \cdot \mathrm{mm}^{2} / \mathrm{m}\right) & \\
\end{array}$ & 184,4 & $x x x x$ & $x x x x$ & ASTM C 611-1998 \\
\hline Cinzas (\%) & 66,7 & $x x x x$ & $x x x x$ & NBR 13926 \\
\hline Materiais Voláteis (\%) & 12,25 & 9,5 & 7,8 & NBR 13927:1997 \\
\hline Densidade Calcinada $\left(\mathrm{g} / \mathrm{cm}^{3}\right)$ & 1,99 & 1,95 & 1,99 & ASTM C 838-1996 \\
\hline Densidade Real $\left(\mathrm{g} / \mathrm{cm}^{3}\right)$ & 2,625 & 2,5 & 2,58 & ASTM C 559-1990 \\
\hline Porosidade (\%) & 24,19 & 22 & 22,87 & PI PO-24-001 \\
\hline Variação Volumétrica (\%) & 11,31 & 6,52 & 5,59 & PI PO-24-001 \\
\hline
\end{tabular}

Segundo o conceito de distribuição granulométrica contínua de partículas, o fator de empacotamento das partículas de diferentes diâmetros contribui significativamente nos principais parâmetros exigidos para esse tipo de material.

Embora cada matéria-prima possua sua particularidade química, a adoção do modelo de distribuição de Andreasen propiciou melhores resultados para as características investigadas. Para maximizar o empacotamento, o coeficiente de distribuição "q" de sua equação deve ser o mais próximo de 0,37 propiciando a máxima densidade para isso tipo de material.

Para a elaboração das massas de tamponamento adotou-se como limites de granulometria, máximo e mínimo o material refratário e a alumina respectivamente.

Assim, foi possível distribuir as frações de fontes de carbono ao longo desses limites, adquirindo o melhor fator de empacotamento possível. A Figura 11 representa o gráfico obtido a partir da distribuição granulométrica para as diferentes massas de tamponamento avaliadas.

\section{Curva granulométrica das Massas Desenvolvidas e a Massa Base}

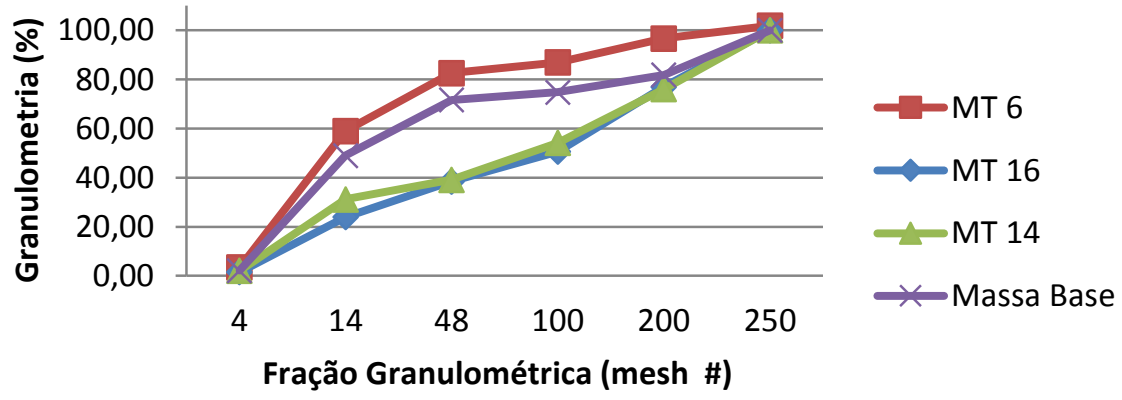

Figura 11. Curva de distribuição granulométrica das massas de tamponamento desenvolvidas.

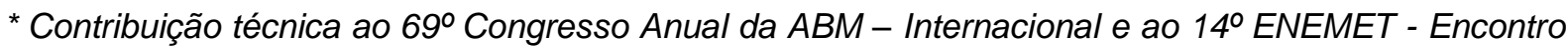
Nacional de Estudantes de Engenharia Metalúrgica, de Materiais e de Minas, 21 a 25 de julho de 2014, São Paulo, SP, Brasil.
} 


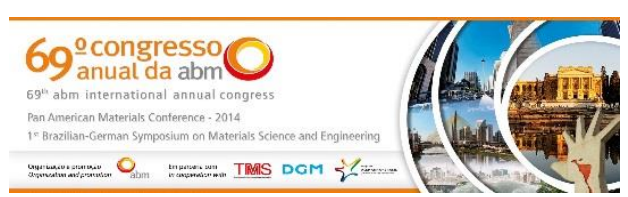

Finalmente, é importante destacar que valores de porosidade aparente médios, após calcinação das massas de tamponamento investigadas, mostraram-se próximos aos valores médios deste mesmo parâmetro para massas de tamponamento à base de alumina, partículas finas, carbeto de silício, sílica, resina, piche, entre as temperaturas de $1000^{\circ} \mathrm{C}-1350^{\circ} \mathrm{C}$, por períodos de $2 \mathrm{~h}$ e $3 \mathrm{~h}$. Por outro lado, a resistência à compressão média mostra-se muito superior aos valores encontrados na literatura.

\section{CONCLUSÃO}

O trabalho desenvolvido apresentou grande resultados e mostra-se promissor para o desenvolvimento e adequação para massas de tamponamento de vários ramos da indústria.

Esse material apresenta liberdade de utilização de várias matérias-primas, desde que se procura manter as propriedades físicas, químicas e metalúrgicas desejadas.

E um produto essencial para indústria siderúrgica, ramo em que merece maior atenção devido ser um mercado amplo e expressivo, além do mais procura constantemente por produtos de menor custo e melhor qualidade.

A série de massas desenvolvidas apresentou grande relevância e resultados positivos no quesito utilização de materiais recicláveis e materiais alternativos. Ela apresenta a oportunidade de consumo de grande parte de rejeitos gerados no processo produtivo da Fábrica de Pasta da Novelis, unidade Ouro Preto. Os resultados indicam a possibilidade de uso de resíduos de alumina, chamote, aglomerantes, existentes na Novelis do Brasil, unidade Ouro Preto, para a produção de várias massas de tamponamento. Para a complementação deste estudo, de modo a estipular a extensão de suas aplicabilidades, tornam-se necessários ainda avaliar a refratariedade, condutividade térmica, resistência à corrosão pela escória, resistência à erosão pelo banho, resistência à oxidação e ao ataque de álcalis de cada uma destas massas de tamponamento.

\section{Agradecimentos}

A empresa Novelis pela oportunidade de aprendizado e pelas amizades formadas, em especial aos Senhores Márcio Guimarães e Marcel Ferri. Aos amigos da Fábrica de Pasta que me ensinaram, apoiaram e proporcionaram desenvolver esse trabalho magnífico, em especial aos Senhores Júlio Santos, Rogério Gualberto e Professor Ithavahn. Exemplos de profissionalismo, conhecimento e humildade.

\section{REFERÊNCIAS}

1 Jameson $\mathrm{D}$, Lungen $\mathrm{H}$, Lao $\mathrm{D}$ - Technical study into the means of prolonging blast furnace campaign life. European Commission, 1995.

2 Wells L. The rheology of a composite polymer ceramic plastic refractory. PhD Thesis. University of Wollongong, 2002.

3 Mitsui H, Toritani Y, Yamasaki S, Oguchi Y, Kawakami T. Recent developments in tap hole for blast furnaces. Aachen Proceedings, 1988, p. 98-102

4 Santos ETB. Avaliação da drenagem de líquidos do cadinho do alto-forno 2 da ArcelorMittal Tubarão através de modelagem física e matemática. Dissertação de Mestrado. Redemat, Escola de Minas, UFOP, 2009.

\footnotetext{
* Contribuição técnica ao 69 Congresso Anual da ABM - Internacional e ao 14ํㅡㄹ ENEMET - Encontro Nacional de Estudantes de Engenharia Metalúrgica, de Materiais e de Minas, 21 a 25 de julho de 2014, São Paulo, SP, Brasil.
} 
5 Pan C-P, Shao C-H. Development of Anti-Splashing Taphole Mud. China steel Technical Report, 2009; 22: 48-52.

6 Cruz Jr R, Perdigão LP, Belonia Filho ESB, Freitas ES, Leite MBB, Amorim BN et al. Utilização do programa seis sigma para a otimização do esgotamento de gusa e escoria no alto forno 01 da Arcelormittal Tubarão - 39 Seminário de Redução de Minérios e Matérias-Primas 10 Simpósio Brasileiro de Minérios de Ferro, Vitória, ES, 2009.

7 Muroi N - New taphole mud for blast furnace. Taikabutsu Overseas, vol. 19, no. 3, p. 2427, 1999.

8 Dash SR - Development of improved tap hole clay for blast furnace tap hole. Master thesis, Department of Ceramic Engineering National Institute of Technology, Rourkela May 2009.

9 Bassalo HC, Bittencourt LRM. Massa de tamponamento para furos de corrida de altosfornos - tipos, projeto de desenvolvimento e adequação às condições operacionais. XXXII Seminário de Redução de Minério de Ferro - Anais ABM, Vila Velha, 2002, p. 349357.

10 Lopes $A B$ - The influence of ferro silicon nitride on the performance of the modern taphole mud for blast furnaces. Refractories Application and News, 2002; 7(5): 26-30.

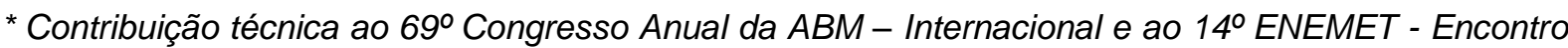
Nacional de Estudantes de Engenharia Metalúrgica, de Materiais e de Minas, 21 a 25 de julho de 2014, São Paulo, SP, Brasil. 